\title{
3. CURRENT KNOWLEDGE OF VENUS
}

\author{
D. M. HUNTEN \\ Kitt Peak National Observatory, Tucson, Ariz., U.S.A. \\ G. E. McGILL \\ University of Massachusetts, Amherst, Mass., U.S.A. \\ and \\ A. F, NAGY \\ University of Michigan, Ann Arbor, Mich., U.S.A.
}

\begin{abstract}
As an introduction to the remaining papers in this issue, a summary is given of our current knowledge of Venus, with emphasis on recent progress and on the contributions to be expected from the Pioneer Venus missions. Headings are surface and interior, clouds and lower atmosphere, dynamics and thermal structure, neutral upper atmosphere, and ionosphere and solar-wind cavity.
\end{abstract}

\section{Introduction}

Seven years ago, Hunten and Goody (1969) examined the state of Venus science and advocated an atmospheric entry mission as the best means to significant further knowledge. Now that this mission exists as part of Pioneer Venus, it is appropriate to discuss the current understanding as it has developed through several Venera probes, the Mariner 10 flyby, Earth-based observations, and theory. More detail can be found in the papers below, in the reviews by Marov (1972), Whitten and Colin (1974), and Friedman and Lewis (1975), and in the June 1975 issue of the Journal of the Atmospheric Sciences, containing papers from a conference on the atmosphere of Venus. Other material from this conference is available as a NASA special publication (Hansen, 1975). A convenient summary of the Venera 9 and 10 results (Keldysh, 1976) was given at the June 1976 meeting of COSPAR.

The present survey is organized into five disciplines, corresponding only partially to those covered by the detailed papers below. A major theme is to contrast the limited, though important, progress made in the last 7 years with the advances to be expected from direct exploration by the Pioneer Venus probes and orbiter and the corresponding Venera missions.

\section{Surface and Interior}

\subsection{OBSERVATIONS}

From the viewpoint of the geologist, Venus is the least understood of the inner planets because the perpetual clouds deprive us of our most useful tool, the photograph. Radar images, though potentially rich in information content, are not 
so easily interpreted as photographs to yield criteria bearing on surface and interior processes and rock types. Despite the unusually difficult conditions, significant progress has nevertheless been made.

The surface environment has also been studied by direct measurement from Venera probes and microwave emission spectra received by radio telescopes. As discussed below, distinctive patterns of radar-bright and radar-dark regions mappable from Earth can be related to variations in topography, small-scale roughness, or physical properties of the surface. By analogy arguments, some of these regions may be correlated tentatively with landforms familiar on other planets. Knowledge of the interior of Venus is based on magnetometer measurements, plus inferences derived from rotation period, inconclusively determined asymmetry of figure and gravity field, and Venera 8-10 $\gamma$-ray spectra.

Table I lists recently published values of parameters of geological and geophysical interest. Many of the listed values are very uncertain. In addition to these specific parameters, much information exists in the form of radar maps and images, and radar altimetry traverses. The low-resolution radar images of Venus exhibit several clearly defined regions that are brighter or darker than immediately adjacent areas. Many of the bright regions and some of the dark regions are crudely circular, and two circular dark regions, each on the order of $1000 \mathrm{~km}$ in diameter, show central bright spots (Campbell et al., 1970). The most prominent bright region, $\alpha$ (or Faraday), shows greater contrasts with its surroundings at a wavelength of $3.8 \mathrm{~cm}$ than it does at $70 \mathrm{~cm}$, indicating either greater roughness at a scale near $3.8 \mathrm{~cm}$, or greater elevation. Two bright areas that also were crossed by altimetry traverses are, in fact, elevated relative to surrounding terrain (Campbell et al., 1972). Relative brightnesses of prominent features in general are interpreted as due to variable elevation and small-scale roughness, rather than variable intrinsic reflectivity of surface materials (Goldstein and Rumsey, 1972; Rogers et al., 1974).

Higher resolution images of small portions of the Venusian surface reveal circular patterns almost certainly due to craters (Rumsey et al., 1974). The most recent images obtained (as of September 1975) reveal not only crater-like forms, but features interpreted as canyons and rilles (Goldstein and Rumsey, 1975). Examples of these recent images are shown by Masursky et al. (1977). The radar resolutions of the best images currently available are about $10 \times 10 \mathrm{~km}$ (Goldstein and Rumsey, 1975), implying a recognition resolution on the order of $50 \mathrm{~km}$ (Saunders et al., 1973). Published images show crater-like forms from about 35 to $160 \mathrm{~km}$ (Saunders et al., 1974). The depth of the $160 \mathrm{~km}$ crater is about 500 meters, an order of magnitude shallower than pristine lunar craters of comparable diameter (Pike, 1974).

The $\gamma$-ray spectra obtained by Venera 8 (Vinogradov et al., 1973) are consistent with uranium, thorium, and potassium abundances characteristic of granitic rocks, and two orders of magnitude too large for undifferentiated chondritic material (Clark et al., 1966). Furthermore, as pointed out by Vinogradov et al. 
TABLE I

\begin{tabular}{|c|c|c|}
\hline Parameter & Value & References \\
\hline Period of rotation & $243.0 \pm 0.1$ earth days & Jurgens, 1970 \\
\hline Mean equatorial radius & $6050.0 \pm 0.3 \mathrm{~km}$ & $\begin{array}{l}\text { Smith et al., } 1970 \\
\text { Campbell et al., } 1972\end{array}$ \\
\hline Mean density & $5.269 \mathrm{~g} \mathrm{~cm}^{-3}$ & Saunders et al., 1973 \\
\hline $\begin{array}{l}\text { Surface equatorial } \\
\text { gravitational acceleration }\end{array}$ & $890 \mathrm{~cm} \mathrm{sec}^{-2}$ & Saunders et al., 1973 \\
\hline Magnetic dipole moment & $<0.0003$ of Earth's moment ${ }^{a}$ & Simpson et al., 1974 \\
\hline Equatorial ellipticity & $1.1 \pm 0.4 \mathrm{~km}^{\mathrm{b}}$ & Smith et al., 1970 \\
\hline $\begin{array}{l}\text { Center of mass/center of } \\
\text { figure offset }\end{array}$ & $\begin{array}{l}1.5 \pm 0.3 \mathrm{~km}^{\mathrm{b}} \text { (center of } \\
\text { mass towards Earth at inferior } \\
\text { conjunction) }\end{array}$ & Smith et al., 1970 \\
\hline $\begin{array}{l}\text { Moment of inertia difference } \\
(B-A) / C\end{array}$ & $3 \pm 3 \times 10^{-4}$ & $\begin{array}{l}\text { Shapiro et al., 1973; } \\
\text { Howard et al., } 1974\end{array}$ \\
\hline Thickness of epilith ${ }^{c}$ & $0.5-1 \mathrm{~m}$ & $\begin{array}{l}\text { Kroupenio, 1972; } \\
\text { Warnock and Dickel, } 1972\end{array}$ \\
\hline Density of epilith & $1.2-1.9 \mathrm{~g} \mathrm{~cm}^{-3}$ & Kroupenio, 1972 \\
\hline Density of rock beneath epilith & $2.2-2.7 \mathrm{~g} \mathrm{~cm}^{-3}$ & Kroupenio, 1972 \\
\hline Surface abundances of & $2.2 \mathrm{ppm} / 6.5 \mathrm{ppm} / 4.0 \%$ & Vinogradov et al., 1973 (V8) \\
\hline \multirow[t]{2}{*}{ uranium/thorium, $_{\text {p }}$ ptassium ${ }^{\mathrm{d}}$} & $0.5 \mathrm{ppm} / 4.0 \mathrm{ppm} / 0.9 \%$ & Keldysh, 1976 (V9) \\
\hline & $0.7 \mathrm{ppm} / 1.1 \mathrm{ppm} / 0.3 \%$ & Keldysh, 1976 (V10) \\
\hline $\begin{array}{l}\text { Total surface relief, } \\
\text { equatorial region }\end{array}$ & $\sim 6 \mathrm{~km}$ & $\begin{array}{l}\text { Campbell et al. } 1972 \text {; } \\
\text { Pettengill (pers. } \\
\text { comm., 1975) }\end{array}$ \\
\hline Surface atmospheric pressure & $93 \pm 1.5 \mathrm{~kg} \mathrm{~cm}^{-2}$ & Marov et al., 1973 \\
\hline Surface atmospheric temperature & $741 \pm 7 \mathrm{~K}$ & Marov et al., 1973 \\
\hline Variation in surface temperature & $\begin{array}{l}<12 \mathrm{~K} \text {, equator to pole } \\
18 \pm 9.2 \mathrm{~K} \text {, limb to limb }\end{array}$ & Sinclair et al., 1970 \\
\hline $\begin{array}{l}\text { Horizontal wind velocity } \\
\text { at surface }\end{array}$ & $\begin{array}{l}0-2 \mathrm{~m} \mathrm{~s}^{-1} \\
0.4-1.3 \mathrm{~m} \mathrm{~s}^{-1}\end{array}$ & $\begin{array}{l}\text { Marov et al., 1973; } \\
\text { Ainsworth and Herman, } \\
\text { 1975; Veneras } 9 \text { and } 10 \\
\text { (Keldysh, 1976) }\end{array}$ \\
\hline
\end{tabular}

a A recent reinterpretation of Venera 4 data by Russell (1976) suggests that the actual moment may be on the order of four times this value.

b Actual uncertainties much larger than formal errors (Smith et al., 1970).

' The term 'regolith' has not been used to avoid a genetic comparison with the lunar regolith.

d Actual uncertainties much greater than formal errors, but considered less than $30 \%$ (Vinogradov et al., 1973). The Venera 9 and 10 data are considerably more uncertain, because the pulse-height analyzer had only 3 channels.

(1973), the elemental ratios among uranium, thorium, and potassium are similar to those for terrestrial igneous rocks (Figure 1). Surficial processes of weathering, erosion, transportation and deposition on the earth tend to destroy these consistent elemental ratios (Clark et al., 1966). The results from Veneras 9 and 10 (Keldysh, 1976) resemble those from terrestrial basalts, further reinforcing the interpretation that differentiated igneous rocks occur on Venus. 

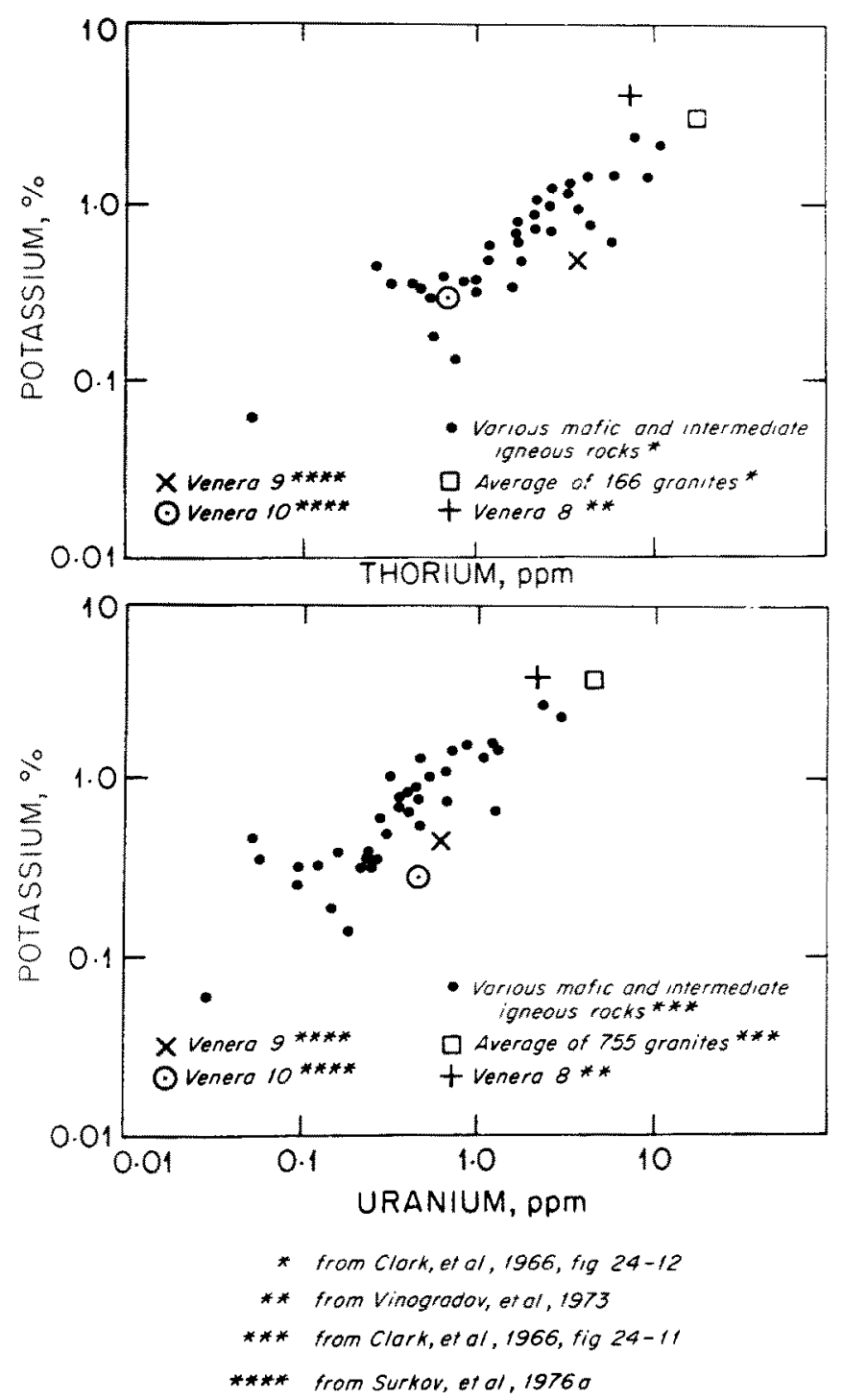

Fig. 1. Systematic variation in potassium, thorium and uranium contents of terrestrial igneous rocks. Venera 8,9 , and $10 \gamma$-ray spectrometer analyses fall close to the elongated cluster of terrestrial points, supporting an igneous origin for the materials analyzed on Venus, and permitting crude estimates of overall rock compositions ('granitic' for Venera 8 sample, 'basaltic' for Venera 9 and Venera 10 samples).

\subsection{THEORY AND DISCUSSION}

Existing data may be discussed conveniently in relation to three major problem areas: (1) bulk composition, degree of differentiation and physical state of the interior; (2) chemical and physical nature of the surface; and (3) exogenic and endogenic processes creating and modifying landforms. 
Interior. The apparent resonant lock with Earth indicated by Venus' rotation period implies, if it is not accidental, an asymmetry in the mass distribution of the planet. Derived center of mass/center of figure offset indicates the existence of the expected asymmetry (Smith et al., 1970; Shapiro et al., 1973; Howard et al., 1974), but the results lack the precision needed to establish the asymmetry beyond doubt. A resonant lock with Earth also implies a liquid interior to produce the tidal friction needed to slow rotation (MacDonald, 1963; Goldreich and Peale, 1967). This requirement, and the apparent existence of igneous rocks at the surface indicated by the Venera 8-10 $\gamma$-ray spectrometers, suggest that the interior of Venus is differentiated, a not unexpected result considering the similarities in diameter and mean density of Venus and Earth. It is interesting to note that Lewis (1970) also predicts a differentiated Venus because quartz $\left(\mathrm{SiO}_{2}\right)$ is present in most of the atmosphere-lithosphere reactions needed to yield the gaseous components of the lower atmosphere.

If it is reasonable to expect that Venus is differentiated and has a liquid core, it also is clear that this does not result in an Earth-like magnetic field (Simpson et al., 1974). A differentiated Venus should have a core not greatly different from the Earth's core; hence the negligible magnetic field is presumably a result of the much slower spin rate of Venus (Van Allen et al., 1967).

Surface. Data concerning the outermost surface layer of Venus are derived from radar studies, which indicate that Venus is smoother at radar wavelengths than either Mercury or the Moon (Kroupenio, 1972; Goldstein, 1972). The best fit to both radio and radar data involves a thin layer of low dielectric constant over a semi-infinite layer of higher dielectric constant, though the agreement between predicted and observed spectra is not very satisfactory for any reasonable combination of dielectric constants (Warnock and Dickel, 1972). Kroupenio (1972) derives a model surface with about $0.5 \mathrm{~m}$ of material with density $1.2-1.9 \mathrm{~g} \mathrm{~cm}^{-3}$ (depending on atmospheric model chosen) overlying material with density 2.2 $2.7 \mathrm{~g} \mathrm{~cm}^{-3}$ (again depending on atmospheric model). The density of the surface layer is typical of loose, porous material, whereas the higher density of the substrate is consistent with densities of common igneous rocks. These earlier estimates are confirmed by the Venera $9-10$ result, $2.7-2.9 \mathrm{~g} \mathrm{~cm}^{-3}$ (Keldysh, 1976).

The calculations of Lewis (1970) indicate that, at the temperature and pressure characteristic of the surface, the atmosphere of Venus will react with most of the major minerals present in common igneous rocks, with consequent loss to the atmosphere of volatile reaction products. Orville (1974) has challenged the validity of several of these reactions, pointing out that the required mineral assemblages are very unlikely, or even impossible. Thus it is not likely that the Venusian atmosphere is buffered by surface rocks as Lewis suggests, but it remains reasonable to assume rapid chemical weathering of exposed rock by the hot and presumably corrosive Venusian atmosphere. This weathering may be responsible for the high porosity and low dielectric constant of the surface layer of 
Venus. Because of the dense Venusian atmosphere, gardening of the surface by numerous small impact events to produce a regolith is not a valid alternative (unless, of course, the dense atmosphere is of recent origin).

Processes forming and modifying landforms. The presence of extensive terrains dominated by large craters on Mars, Mercury or the Moon is excellent evidence that global recycling of crustal rocks into the mantle has not taken place since the formation of the craters. Geological studies conclusively demonstrate the great age of these cratered terrains, a conclusion that has been verified for the Moon by radiogenic age determinations. Thus it can be stated with some confidence that plate tectonics has not been an active process on the Moon for most of solar system history, and has not affected at least significant portions of Mercury and Mars for a period of comparable duration. In marked contrast, the Earth has been and still is subjected to plate tectonics. Is there a Venusian plate tectonics? The appearance of large craters on some recent radar images (Rumsey et al., 1974; Goldstein and Rumsey, 1975) indicates the possibility of extensive cratered terrain and therefore a lack of plate tectonics. It is really too early to judge, because of the small areal coverage now available.

The morphology of the single large crater for which three dimensional data exist is, unfortunately, subject to multiple interpretations. The size and raised rim of the crater favor (but do not prove) an impact origin, but its shallowness could be due to a number of causes, including flooding by lava, filling by particulate material transported by the atmosphere, or rise of the floor and sag of the rim due to rock creep or isostatic rebound. The role of rock creep near the surface of Venus is particularly difficult to evaluate because experiments designed to determine the rheology of common rocks usually imitate conditions on Earth where high temperatures coexist with high pressures.

The atmosphere is the only obvious fluid that could modify the surface of Venus by moving. The $0.4-1.3 \mathrm{~m} \mathrm{~s}^{-1}$ wind velocities reported by Veneras 9 and 10 (Keldysh, 1976) should cause extensive erosion and transportation. Because of the density of the Venusian atmosphere, threshold friction velocities as low as $1-2 \mathrm{~cm} \mathrm{~s}^{-1}$ are capable of eroding loose particulate matter (Hess, 1975; Sagan, 1975). Surface winds would be far more effective in eroding and transporting material than terrestrial winds of similar velocity because of the greater density of the Venusian atmosphere.

\subsection{MAJOR UNKNOWNS AND CONTRIBUTIONS OF PIONEER VENUS}

The 1978 Pioneer Venus missions will refine the values for the asymmetry of figure and gravity field from radar altimetry and radio tracking. The combined gravity and figure data also can yield information on the degree of isostatic compensation, and on the coarse structure of the crust. The greatly increased areal coverage by radar imagery and altimetry will indicate if any continentalscale elevation differences exist, implying differentiation into contrasting crustal 
rock types. Also, major terrain features indicative of the presence or absence of an active plate tectonics may be evident in the radar images. Finally, measurements of near-surface wind velocity and atmospheric composition will permit improved models for processes modifying the Venusian surface.

\section{Clouds and Lower Atmosphere}

The deep, dense, and planetwide cloud deck is a major distinguishing feature of Venus. It must surely play a major part in the maintenance of the high surface temperature by helping to block infrared radiation, and it controls the penetration of the solar input. Its composition, along with that of the atmospheric gases, should give important clues to the geochemistry of Venus' surface and interior (Lewis, 1970).

Despite the pessimism expressed by Hunten and Goody (1969), the major component of the visible clouds has been identified as concentrated sulfuric acid (Young, 1975). Evidence for this identification was given by Sill (1972) and Young (1973), who pointed out that the physical properties of concentrated sulfuric acid were in good agreement with the refractive index and sphericity of the cloud particles, deduced from polarization data by Hansen and Arking (1971) and Hansen and Hovenier (1974). In addition, Pollack et al. (1974, 1975) obtained infrared spectra of Venus with an airborne telescope and tried to fit them with a large number of candidate materials. Only concentrated sulfuric acid was compatible, and this material was required to extend to a very large optical depth below the cloud tops. An upward-looking photometer aboard Venera 8 has shown that a significant amount of solar radiation does penetrate to the surface; this light was used for the Venera 9 and 10 surface photographs. Lacis and Hansen (1974) and Lacis (1975) have shown however that a very wide variety of cloud models can account for the data. The Venera 8 data suggested that the clouds might extend only from their top at $67 \mathrm{~km}$ to $30 \mathrm{~km}$, but Wofsy and Sze (1975) suggested that $\mathrm{H}_{2} \mathrm{SO}_{4}$ would thermally dissociate below $45-50 \mathrm{~km}$. The results of Veneras 9 and 10 are in close agreement, showing a sharp cloud bottom at $49 \mathrm{~km}$ (Marov et al., 1976). Below this level to the end of the measurements at $18 \mathrm{~km}$ there seems to be only a small number of larger particles. In the main cloud, the mean size and refractive index agree with those obtained by Earthbased polarimetry.

One unexplained feature of the visible cloud is its yellow coloration: it absorbs weakly in the blue and more strongly in the ultraviolet. The absorption is distinctly patchy and reveals a wealth of dynamic structure through a nearultraviolet filter. Such a filter was used on the Mariner 10 camera (Murray et al., 1974), on the basis of earlier indications from the ground. Elemental sulfur has a suitable absorption spectrum and is chemically plausible, but it is hard to see why sulfur should appear, and disappear, in the manner observed (Young, 1975; Hunten, 1975). 
A plausible model for the production and maintenance of the cloud, yielding both sulfur and sulfuric acid, has been put forward by Prinn (1975). After particles have fallen to great depths, the sulfur is supposed to be thermally converted to COS, which then mixes back up to the cloud tops and is photochemically oxidized. But there are several steps in this cycle that must be postulated for lack of quantitative data. That COS is not observed spectroscopically may be explained by its rapid destruction once it reaches the visible atmosphere.

The composition of the atmosphere is summarized in Table II. The dominance of $\mathrm{CO}_{2}$ had been surmised but not proved by spectroscopists before the direct measurements by several Venera probes. These results, taken literally, leave $7 \%$ or less for inert gases such as argon and nitrogen. But the experiments were designed before the presence of sulfuric acid droplets was realized; it is conceivable that the fraction of inert gases could be somewhat larger (Belton, 1975). The early in-situ result for $\mathrm{H}_{2} \mathrm{O}$, as large as $2 \%$, is in conflict with the upper limit of $0.1 \%$ from microwave data (Pollack and Morrison, 1970; Rossow and Sagan, 1975). Indeed, Veneras 9 and 10 have found $0.1 \%$ in the region below the cloud base. The microwave analysis also yields a mixing ratio for $\mathrm{H}_{2} \mathrm{SO}_{4}$ in the cloud droplets or in some vapor form at lower altitudes. All the other data are spectroscopic and refer to the gas near and above the cloud tops. $\mathrm{H}_{2} \mathrm{O}$, a component of the clouds, is expected and observed to be less abundant there. $\mathrm{O}_{2}$ is remarkably rare, considering that it must be produced continuously by ultraviolet photolysis of $\mathrm{CO}_{2}$. Of note is the presence of traces of $\mathrm{HCl}$ and $\mathrm{HF}$, as well as the $\mathrm{H}_{2} \mathrm{SO}_{4}$ in the cloud particles. The helium result is obtained from a dayglow measurement by Mariner 10, and incorporates an uncertain correction for diffusive separation of $\mathrm{He}$ and $\mathrm{CO}_{2}$.

TABLE II

Composition of the Venus atmosphere

$(\mathrm{ppm}=$ parts per million $)$

\begin{tabular}{lll}
\hline Gas & $\begin{array}{l}\text { Molar } \\
\text { mixing ratio }\end{array}$ & References \\
\hline $\mathrm{CO}_{2}$ & $93-100 \%$ & Vinogradov et al. $(1971)$ \\
$\mathrm{Ar}+\mathrm{N}_{2}$ & $0-7 \%$ & ibid. \\
$\mathrm{H}_{2} \mathrm{O}$ & $0.3-2 \%$ & ibid. \\
& $<0.1 \%$ & Rossow and Sagan (1975) \\
& $0.1 \%$ & Keldysh (1976) \\
$\mathrm{Above}_{2}$ clouds: & $(0.5-40) \mathrm{ppm}$ & Barker (1975) \\
$\mathrm{H}_{2} \mathrm{SO}_{4}$ & $\sim 10 \mathrm{ppm}$ & Rossow and Sagan (1975) \\
$\mathrm{CO}$ & $50 \mathrm{ppm}$ & L. Young (1972) \\
$\mathrm{HCl}$ & $0.4 \mathrm{ppm}$ & ibid. \\
$\mathrm{HF}$ & $0.01 \mathrm{ppm}$ & ibid. \\
$\mathrm{O}_{2}$ & $<1 \mathrm{ppm}$ & Traub and Carleton (1974) \\
$\mathrm{He}$ & $10 \mathrm{ppm}$ & Kumar and Broadfoot (1975) \\
\hline
\end{tabular}


The concept of the Pioneer Venus large probe is in large part tailored to the questions that flow from the above discussion. Gases and vapors to the partper-million level or better will be impartially measured by the mass spectrometer (LNMS), supplemented for certain ones by the gas chromatograph (LGC). Cloudparticle composition will not be measured directly, unless one should lodge on the inlet and evaporate there. But the corresponding vapor will be detected below the cloud layer. Simultaneous information will be available on temperature (LAS, SAS), particle-size distribution (LCPS), scattering coefficient (LN), and solar radiation (LSFR). There should thus be no difficulty in reconstructing a complete description of the cloud. Dust or a highly involatile photochemical smog may not yield to this approach; if they are encountered, their analysis will have to wait for another mission. The same is probably true of the matter that colors the visible clouds.

\section{Dynamics and Thermal Structure}

It is now well established that there is a retrograde circulation at a speed of order $100 \mathrm{~m} \mathrm{~s}^{-1}$ at the cloud tops. Earth-based photographic observations ( reviewed by Dollfus, 1975) and Doppler shifts (Traub and Carleton, 1975) are in agreement on the direction and the order of the speed. The images from Mariner 10 confirm these results, and permit an evaluation of the wind speed as a function of latitude (see Schubert et al., 1977). The motion does not closely resemble solid-body rotation; the colloquial term 'four-day rotation' is inappropriate. At deeper altitudes, a single component of the motion has been measured by Venera probes (Keldysh, 1976), the velocities decrease to a very small value below $10 \mathrm{~km}$. Several mechanisms have been proposed to account for the motion, and further observational input is needed to decide among them.

Until recently it seemed that the deep circulation and thermal structure might be explained by some version of the Goody-Robinson (1966) mechanism. They postulated that solar energy was absorbed near the cloud tops, and drove a planetary-scale eddy. They further speculated that the descending branch of the eddy might keep the lower atmosphere hot by adiabatic compression. A numerical model based, like the Goody-Robinson model, on the Boussinesq approximation, gave similar results. However, when the Boussinesq approximation was partially removed, the eddy did not penetrate much deeper than the layer that receives the solar energy (Kálnay de Rivas, 1973). More recent calculations (Kálnay de Rivas, 1975) confirm this result and show that only when the greenhouse effect is strong does the circulation penetrate all the way down to the surface. The infrared optical depth required is of the order of 500 . In agreement with these numerical results, Stone (1975) has argued that the eddy can only transport heat upwards. Such a model has much in common with a greenhouse model, but treats explicitly the horizontal redistribution of heat that is assumed at the outset for a greenhouse. Similar results are reported by Pollack and Young 
(1975), who put emphasis on a detailed treatment of radiation transfer, both solar and infrared, the results of which are used in a dynamical computation. Constraining their radiative calculations to be consistent with the Venera 8 photometer results and allowing for the important contribution of cloud aerosols to the thermal infrared opacity, Pollack and Young showed that the greenhouse effect can account for the high surface temperature. It can be concluded that the greenhouse is the fundamental mechanism that maintains the hot surface.

The Venera probes (Keldysh, 1976) suggest a diurnal temperature variation of $30-50 \mathrm{~K}$ from 30 to $60 \mathrm{~km}$, in strong contrast to most models and to occultation results (Fjeldbo et al., 1971).

The circulation of the thermosphere has received study in a series of papers summarized by Dickinson and Ridley (1975). They find a single Hadley cell directed from the subsolar to the antisolar region, with winds around $300 \mathrm{~m} \mathrm{~s}^{-1}$ near the terminator at high levels. The dissociation products $\mathrm{O}$ and $\mathrm{CO}$ are carried away from the day side and accumulate in a rather large region on the night side. The steady-state amounts remaining on the day side are larger by a factor 4 than other current ideas suggest (Section 5 below). If these ideas are correct, the motion may need to be supplemented by local vertical mixing or 'eddy diffusion'. Dickinson and Ridley comment that such motions would weaken their planetary-scale circulation.

All these models are badly in need of more observational feedback, which will be provided in depth by both Pioneer Venus missions. Penetration and absorption of solar radiation will be measured by radiometers on the large probe (LSFR) and the one small probe that enters on the day side. Infrared fluxes will be measured by the large probe (LIR) and the other two small probes (SNFR). The orbiter will measure upward fluxes and will give detailed information on cloud-particle properties in the visible layer (OIR, OCPP). Spin-scan imaging will extend the time base of Mariner 10 (less than 2 weeks) to at least a Venus year (OCPP). Visible and infrared opacities due to gases and aerosols will be inferred from the composition measurements (LNMS, LGC) and from radiometers (LIR, LSFR) in several wavelength bands aboard the large probe. Horizontal temperature contrasts, and therefore the drives for the circulation, will be measured (or upper limits set) by comparison of the four probes (LAS, SAS) and, at higher levels, by the orbiter (OIR). Accurate tracking of the probes (DLBI) will give wind speeds and directions as a function of height.

\section{Neutral Upper Atmosphere}

This section concentrates on the aeronomy and mean thermal structure of the region above the cloud tops; the general circulation has been discussed in the previous section.

Until recently, it has been conventional to take the exospheric temperature as $700 \mathrm{~K}$, based mainly on model ionospheres dominated by $\mathrm{CO}_{2}^{+}$. Some difficulties 
with the hydrogen budget were pointed out by Hunten (1973), who advocated a temperature near $400 \mathrm{~K}$. A model incorporating lighter ions $\left(\mathrm{O}^{+}\right.$and $\left.\mathrm{O}_{2}^{+}\right)$at $350 \mathrm{~K}$ was published by Kumar and Hunten (1974). By this time, the ultraviolet spectrometer on Mariner 10 had settled the question, giving $400 \mathrm{~K}$ from the hydrogen scale height (Broadfoot et al., 1974). From helium, Kumar and Broadfoot (1975) find $375 \pm 105 \mathrm{~K}$.

Temperatures in the stratosphere and mesosphere are obtained by radio occultation experiments, supplemented by computations of the energy balance (Howard et al., 1974; McElroy, 1969). Typically, the height of the ionospheric peak calculated for such a profile is too high by about a scale height (e.g., Kumar and Hunten, 1974). This effect would be cured if temperatures in the mesosphere and lower thermosphere were somewhat lower. Such a change is probably not incompatible with the data; occultation temperatures are very uncertain for the top 3-5 scale heights (Wasserman and Veverka, 1973; Hunten and Veverka, 1976). On the other hand, the discrepancy, which exists also for Mars, may lie somewhere in the ionospheric models.

Kumar and Hunten (1974) also addressed the hydrogen budget, which has been discussed in more detail by Liu and Donahue (1975) and Sze and McElroy (1975). Both Mariner 5 and Mariner 10 found strikingly low densities of $\mathrm{H}$ atoms in the Venus corona, a result over which many models have stumbled. The current consensus is that a large eddy coefficient, or its equivalent in a large-scale circulation, is required to sweep downwards the atoms produced by dissociation of $\mathrm{H}_{2}$. Eddy coefficients $K=10^{8} \mathrm{~cm}^{2} \mathrm{~s}^{-1}$ or somewhat greater are required; they also deplete the thermosphere of $\mathrm{CO}$ and $\mathrm{O}$ as required by many ionospheric models. Correspondingly, the homopause (or 'turbopause') is at or above $145 \mathrm{~km}$, higher than the ionospheric peak.

A possible alternative is a large nonthermal escape flux of hydrogen, close to $10^{8}$ atoms $\mathrm{cm}^{-2} \mathrm{~s}^{-1}$. There is indeed strong evidence from Mariner-5 data for nonthermal $\mathrm{H}$ atoms, but the corresponding loss rate is 20-100 times smaller (Kumar and Hunten, 1974; Hunten and Donahue, 1976). All escape processes are inhibited by the small $\mathrm{H}$ density.

The circulation model of Dickinson and Ridley (1975) gives an $O$ mixing ratio at the ionospheric peak of $4 \%$. The equivalent eddy coefficient for a global-mean model is $6 \times 10^{6} \mathrm{~cm}^{2} \mathrm{~s}^{-1}$ (Sze and McElroy, 1975, Figure 5). This number should be doubled to refer it to the day hemisphere and make it comparable with the Dickinson-Ridley result. This value, $10^{7} \mathrm{~cm}^{2} \mathrm{~s}^{-1}$, seems to be an order of magnitude too small to account for the hydrogen. Either nonthermal escape is important, or large-scale circulation is not the dominant transport mechanism in the thermosphere.

There are two sources of information on the eddy coefficient in the stratosphere. Prinn $(1974,1975)$ has used as his input the deviation from perfect mixing of the stratospheric haze, obtaining upper limits of $2 \times 10^{5} \mathrm{~cm}^{2} \mathrm{~s}^{-1}$ around $100 \mathrm{mb}$ and $7 \times 10^{4} \mathrm{~cm}^{2} \mathrm{~s}^{-1}$ around $15 \mathrm{mb}$. Sze and McElroy (1975) studied the 
downward flow of $\mathrm{O}_{2}$ from its source in the thermosphere and mesosphere to a sink at the cloud tops. If this flow is too slow, the density builds up and violates the $1 \mathrm{ppm}$ upper limit on the $\mathrm{O}_{2}$ density (Table II). Their lower limit for the 'stratosphere' is $3 \times 10^{5} \mathrm{~cm}^{2} \mathrm{~s}^{-1}$. These results are compatible within reasonable error limits and suggest $K \sim 2.5 \times 10^{5} \mathrm{~cm}^{2} \mathrm{~s}^{-1}$ for the stratosphere with a possible decrease before the approach to the large thermospheric value.

For a number of years the central problem of $\mathrm{CO}_{2}$ aeronomy was the remarkably small degree of dissociation into $\mathrm{CO}$ and $\mathrm{O}$ (or $\mathrm{O}_{2}$ ). The Fifth Arizona Conference on Planetary Atmospheres (1971) was focused on this question. For Venus, the key seems to be catalysis by the HCl-odd hydrogen photochemical system. Prinn (1971), amplifying a suggestion by McElroy, put forward the first model, and a more complete treatment has been given by McElroy et al. (1973) and Sze and McElroy (1975). Oxidation of $\mathrm{CO}$ is by reaction with $\mathrm{OH}$ : production and recycling of $\mathrm{OH}$ is initiated by photolysis of $\mathrm{HCl}$. There may also be direct reaction of $\mathrm{CO}$ with oxides of chlorine. These reactions are effective in the lower stratosphere; sweeping downward of photolysis products from greater altitudes has been discussed above.

Pioneer Venus is expected to make a definitive measurement of the homopause height, and therefore of the effective eddy diffusion coefficient for the lower thermosphere. The probe-bus may actually make mass-spectrometer measurements (BNMS) of gases with different molecular weights right through the homopause. Even if it does not, the results of this vehicle and the orbiter (ONMS) can be compared with those of the large probe (LNMS). Thermospheric and exospheric temperatures will be obtained from the various scale heights measured in-situ by the mass spectrometer (ONMS) and remotely by the ultraviolet spectrometer (OUVS). Mesospheric and stratospheric temperatures will be measured by the infrared (OIR) and occultation experiments on the orbiter. Diurnal variations of $\mathrm{O}, \mathrm{CO}$, and other gases, such as predicted by Dickinson and Ridley (1975) will be observed by the orbiter as the planet swings around the Sun. A real check of the photochemistry of the stratosphere requires measurements of free radicals in small concentrations, a task suited to neither the vehicles nor the instruments of Pioneer Venus. Nevertheless, the mission, though tailored primarily to other height regions, will have a substantial impact on our understanding of the stratosphere and mesosphere.

\section{Ionosphere and Solar-Wind Cavity}

Our sources of direct information on the ionosphere of Venus are the radio occultation measurements of Mariner 5 and Mariner 10 (Kliore et al., 1967; Fjeldbo et al., 1975). These observations showed well-developed day side ionospheres with apparent ionopauses at about 500 and $350 \mathrm{~km}$, respectively (Figure 2). Both spacecraft also found ionization on the night side; the Mariner 10 results showed the presence of two sharp ionization layers at about 142 and $124 \mathrm{~km}$ 


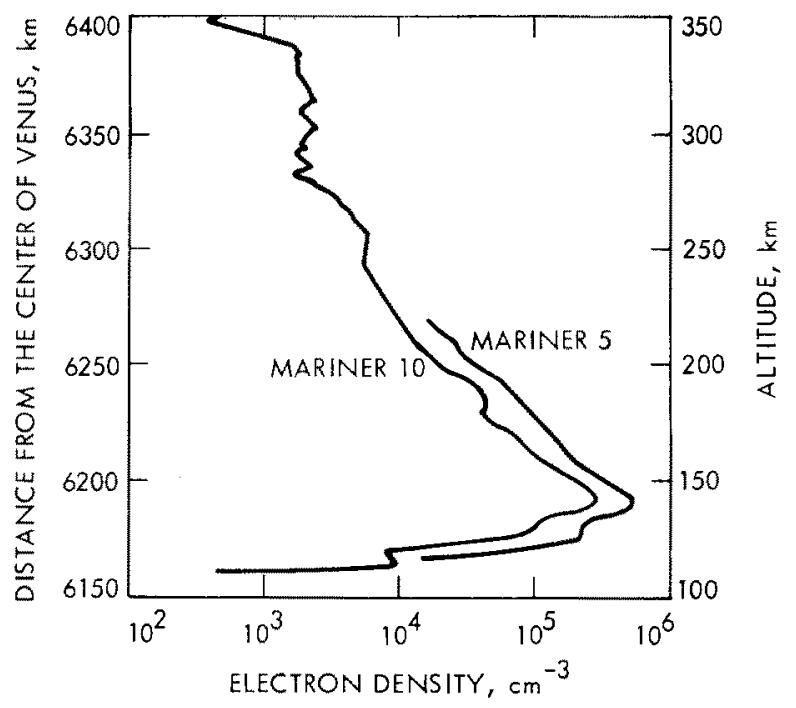

Fig. 2. Dayside electron-density profiles from the occultation experiments on Mariners 5 and 10 (Fjeldbo et al., 1975).

while the data from Mariner 5 showed an ionization peak at $142 \mathrm{~km}$ and the possibility of one or more layers below that level. Similar profiles, with striking temporal variability, have been seen by Veneras 9 and 10 (Keldysh, 1976). Mariner . 5 also indicated an electron density of about $3 \times 10^{3} \mathrm{~cm}^{-3}$ at $200 \mathrm{~km}$, while Mariner 10 found the electron density to drop to less than $2 \times 10^{2} \mathrm{~cm}^{-3}$ above $170 \mathrm{~km}$; this apparent discrepancy may be due either to changes in solar conditions or difficulties in interpretation of Mariner 5 data.

Various models of the Venus dayside ionosphere were developed to fit the Mariner 5 observations (e.g. McElroy, 1969; Herman et al., 1971). Studies of the ionospheric thermal structure also have been presented (Whitten, 1969; Herman et al., 1971), but these calculations had to parameterize the solar-wind energy input due to the lack of any information. Kumar and Hunten (1974) presented a revised and comprehensive ionospheric model based on a careful reinterpretation of the Mariner 5 data. As noted above, they supported a low exospheric temperature of the order of $350 \mathrm{~K}$.

The Mariner 10 results provided the impetus for further modeling studies. Bauer and Hartle (1974) succeeded in fitting the new observational data by assuming a very high atomic oxygen concentration and taking into consideration the dynamic interaction of the solar wind with the ionosphere. This work assumed an $\mathrm{O} / \mathrm{CO}_{2}$ ratio of about 60 at $180 \mathrm{~km}$, much too high a value according to the previous section. An ionospheric model using significantly lower oxygen concentrations and temperature-dependent dissociative recombination rates was published recently by Nagy et al. (1975); it is basically similar to the Kumar and Hunten (1974) model and is successful in reproducing the Mariner 5 and 10 


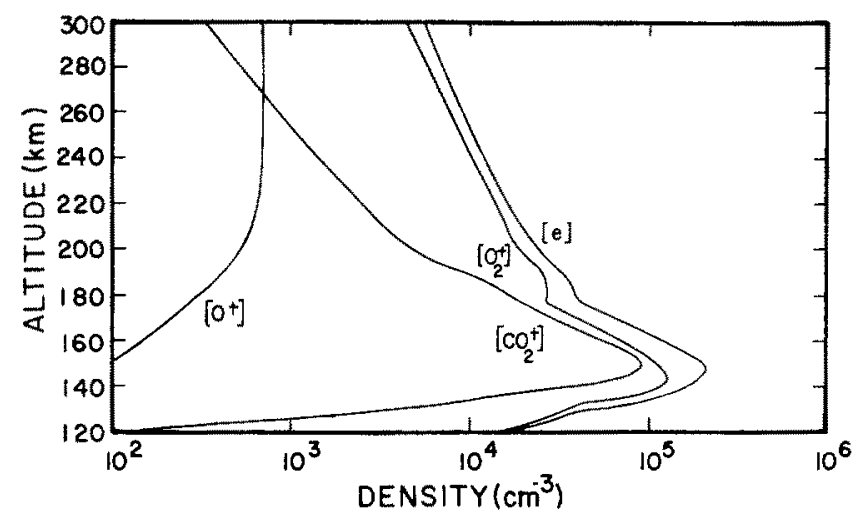

Fig. 3. A model of the daytime ionosphere for the time of Mariner 10 encounter (Nagy et al., 1975).

observations in the chemically controlled regions of the ionosphere (Figure 3). A somewhat similar comprehensive model was also developed by Butler (1975).

Observations of the airglow near the 1304 and $1356 \AA$ lines of atomic oxygen have been attempted from flyby spacecraft (e.g., Kurt et al., 1968; Barth et al., 1967; Broadfoot et al., 1974) and rockets (e.g., Moos et al., 1969; Rottman and Moos, 1973). The atomic oxygen densities deduced from these observations by Strickland (1973) and Rottman and Moos (1973) are relatively high. Recent work (Liu and Donahue, 1975; Nagy et al., 1975; Sze and McElroy, 1975) indicates that such high values are difficult to reconcile and thus the high observed airglow intensities may be caused by either an unexpected source mechanism or contamination by some nearby emission. Zipf $(1975)$ has pointed out that $\mathrm{CO}_{2}^{+}$emissions at high temperatures are a likely source of contamination.

Modeling of the upper ionosphere in the region where solar-wind interactions are significant is an extremely difficult problem because of the large number of factors that have to be taken simultaneously into account. Both the ionosphere and the solar wind, as well as their interaction, must be described; the intrinsic magnetic field, even if present, is too weak to have much effect. The ionospheric models mentioned above have necessarily parameterized many factors; meaningful progress requires direct observational data.

The observed nighttime ionosphere is a puzzle because the night is so long (58 Earth days). The qualitative suggestions available require either an efficient transport process from the day side or a direct nighttime ionization source. McElroy and Strobel (1969) and Banks and Axford (1970) suggested that light ions are transported by either horizontal wind or electrodynamic fountain effects from the day side to the upper nighttime region, but there are many difficulties with even these qualitative proposals and furthermore they do not explain the sharp ionization layers at low altitudes. Very recently Butler (1975) proposed that the low altitude ionization layers are due to two separate mechanisms, both relying on the flow of ionization from the day side to the night side; the lower 
feature is the remnant of the main dayside peak consisting primarily of $\mathrm{O}_{2}^{+}$which has flowed around from the day side while the upper feature is maintained by the flow of atomic ions mainly $\mathrm{O}^{+}$.

The particle and field experiments aboard Mariner 5 and 10, Venera 4 and 6 and more recently Venera 9 and 10 (Gringauz et al., 1976, Vaisberg et al., 1976), confirmed the existence of a bow shock around the planet. Figure 6 of Bauer et al. (1977), reproduced from the work of Vaisberg et al. (1976), shows the trajectories of various spacecraft and indications of several types of interaction regions. The limited observational data on the ionopause were indicated earlier.

A number of theoretical studies of the interaction of the solar wind with nonmagnetic planets have been carried out during the last few years. Michel (1971) reviewed the different basic models and discussed the various assumptions and limitations inherent in them. The calculations of Spreiter et al. (1970) were based on the balance between the pressure of the flowing plasma and the gas pressure of the stationary ionosphere and atmosphere. The ionopause and bow shock were obtained from the continuum equations of gas dynamics for a variety of ratios $H / r_{0}$ of the scale height to the planetary radius. These calculations assumed an isothermal ionosphere and neglected magnetic field effects, but are certainly reasonable considering our present state of ignorance. Cloutier and Daniell (1973) calculated the current due to the induced $\mathbf{v} \times \mathbf{B}$ electric field in the upper ionosphere, which cancels out the shock compressed solar wind field. These various simple models have been fairly successful in predicting bow shock and ionopause positions, but are inadequate for treating the various aspects of the interaction (e.g., energy transfer, mass motions) quantitatively.

None of the papers discussed above incorporated the possible $30 \gamma$ intrinsic magnetic field inferred by Russell (1976). Indeed, such a field is too weak to stand off the solar wind except near the limbs, and should therefore cause only minor corrections in most models.

At almost every point in this discussion we see the fragmentary nature of the data base for the ionosphere and solar-wind cavity, and the large number of different models that run up against a wall of ignorance. Pioneer Venus orbiter, supplemented by the probe bus, will carry an effective complement of aeronomy instruments to heights near the ionospheric peak; this payload will be only slightly inferior, except for data rate, to many in Earth orbit. The solar-wind and magnetic-field instruments (OPA, OEFD, OMAG), though less comprehensive, will still be very informative. The bow shock and cavity will be studied, not only by these sensors, but by measurements of the composition and energetics of the upper ionosphere and ionopause (OETP, ORPA, OIMS, BIMS). The denser parts of the ionosphere will be studied, along with the neutral atmosphere (ONMS, OUVS, BNMS), by measurement of densities, temperatures, and altitude and diurnal variations. Apart from the data rate, the principal limitation is the nature of the orbit, which is a compromise among many conflicting requirements. The near and far environments of Venus are well covered, but there is a large gap at 
intermediate heights and low latitudes. Some information from this region may be provided by Veneras 9 and 10 , but they lack the information about the ionosphere. We expect to obtain a real understanding of Venus' ionosphere and its interaction with the solar wind.

\section{References}

Ainsworth, J. E. and Herman, J. R.: 1975, J. Geophys. Res. 80, 173.

Banks, P. M. and Axford, W. I.: 1970, Nature 225, 924.

Barker, E. S.: 1975, Icarus 25, 268.

Barth, C. A., Pearce, J. B., Kelly, K. K., Wallace, L., and Fastie, W. G.: 1967, Science 158, 1675.

Bauer, S. J. and Hartle, R. E.: 1974, Geophys. Res. Lett. 1, 7.

Bauer, S. J., Brace, L.H., Hunten, D. M., Intriligator D. S., Knudsen W. C., Nagy, A. F., Russell, C. T., Scarfe, F. L., Wolfe, J. H.: 1977, this volume, p. 413.

Belton, M. J. S.: 1975, in J. E. Hansen (ed.), The Atmosphere of Venus, NASA SP-382, p. 114.

Broadfoot, A. L., Kumar, S., Belton, M. J. S., and McElroy, M. B.: 1974, Science 183, 1315.

Butler, D. M.: 1975, 'The Ionosphere of Venus', Ph.D. Thesis, Rice University.

Campbell, D. B., Dyce, R. B., Ingalls, R. P., Pettengill, G. H., and Shapiro, I. I.: 1972, Science 175, 514.

Campbell, D. B., Jurgens, R. F., Dyce, R. B., Harris, F. S., and Pettengill, G. H.: 1970, Science 170, 1090.

Clark, S. P., Jr., Peterman, Z. E., and Heier, K. S.:1966, in S. P. Clark, Jr. (ed.), Handbook of physical constants: Geol. Soc. America Mem. 97, 521.

Cloutier, P. A. and Daniell, R. E.: 1973, Planet, Space Sci. 21, 463.

Dickinson, R. E. and Ridley, E. C.: 1975, J. Atmos. Sci. 32, 1219.

Dollfus, A.: 1975, J. Atmos. Sci. 32, 1060.

Fifth Arizona Conference on Planetary Atmospheres: 1971, J. Atmos. Sci. 28, 833.

Fjeldbo, G., Kliore, A. J., and Eshleman, V. R.: 1971, Astron. J. 76, 123.

Fjeldbo, G., Seidel, B., and Sweetnam, D.: 1975, J. Atmos. Sci 32, 1232.

Friedman, L. D. and Lewis, J. S.: 1975, Astronautics and Aeronautics 13 (5), 46.

Goldreich, P. and Peale, S.: 1967, Astron. Jour. 72, 662.

Goldstein, R. M.: 1972, Icarus 17, 571.

Goldstein, R. M. and Rumsey, H. C.: 1972, Icarus 17, 699.

Goldstein, R. M. and Rumsey, H. C.: 1975, Trans. Am. Geophys. Union 56, 388.

Goody, R. and Robinson, A.: 1966, Astrophys. J. 146, 339.

Gringauz, K. I., Bezrukikh, V. V., Breus, T. K., Gombasi, T., Remizov, A. P., Verigins, M. I., Volkov, G. I.: 1976, Proc. Int. Sym. on Solar-Terrestrial Relations, in press.

Hansen, J.E. (ed.): 1975, The Atmosphere of Venus, NASA SP-382.

Hansen, J.E. and Arking, A.: 1971, Science 171, 669.

Hansen, J. E. and Hovenier, J. W.: 1974, J. Atmos. Sci. 31, 1137.

Herman, J. R., Hartle, R. E., and Bauer, S. J.: 1971, Planet, Space Sci. 19, 443.

Hess, S. L.: 1975, J. Atmos. Sci. 32, 1076.

Howard, H. T., Tyler, G. L., Fjeldbo, G., Kliore, A. J., Levy, G. S., Brunn, D. L., Dickinson, R., Edelson, R. E., Martin, W. L., Postal, R. B., Seidel, B., Sesplaukis, T. T., Shirley, D. L., Stelzried, C. T., Sweetnam, D. N., Zygielbaum, A. I., Esposito, P. B., Anderson, J. D., Shapiro, I. I., and Reasenberg, R. D.: 1974, Science 183, 1297.

Hunten, D. M.: 1973, J. Atmos. Sci. 30, 1481.

Hunten, D. M.: 1975, J. Atmos. Sci. 32, 1262.

Hunten, D. M. and Donahue, T. M.: 1976, Ann. Rev. Earth Planet Sci. 4, 265.

Hunten, D. M. and Goody, R. M.: 1969, Science 165, 1317.

Hunten, D. M. and Veverka, J.: 1976, in A. M. J. Gehrels (ed.), Jupiter, Univ. of Arizona Press, p. 247.

Jurgens, R. F.: 1970, Radio Sci. 5, 435. 
Kálnay de Rivas, E.: 1973, J. Atmos. Sci. 30, 763.

Kálnay de Rivas, E.: 1975, J. Atmos. Sci. 32, 1017.

Keldysh, M. V.: 1976, presented at the 19th COSPAR meeting, Philadelphia.

Kliore, A. J., Levy, G. S., Cain, D. L., Fjeldbo, G., and Rasool, S. I.: 1967, Science 158, 1683.

Kroupenio, N. N.: 1972, Icarus 17, 692.

Kumar, S. and Broadfoot, A. L.: 1975, Geophys. Res. Lett. 2, 357.

Kumar, S. and Hunten, D. M.: 1974, J. Geophys. Res. 79, 2529.

Kurt, V. G., Dostovalow, S. B., and Sheffer, E. K.: 1968, J. Atmos. Sci. 25, 668.

Lacis, A. A.: 1975, J. Atmos. Sci. 32, 1107.

Lacis, A. A. and Hansen, J. E.: 1974, Science 184, 979.

Lewis, J. S.: 1970, Earth Planet, Sci. Lett. 10, 73.

Liu, S. C. and Donahue, T. M.: 1975, Icarus 24, 148.

MacDonald, G. J. F.: 1963, Space Sci. Rev. $2,473$.

Marov, M. Ya.: 1972, Icarus, 16, 455.

Marov, M. Ya., Avduevsky, V.S., Borodin, N. F., Ekonomov, A.P., Kerzhanovich, V. V., Lysov, V. P., Moshkin, B. Ye., Rozhdestvensky, M. K., and Ryabov, O. L.: 1973, Icarus 20, 407.

Marov, M. Ya., Lebedev, V. N., Lystsev, V.E., Kuznetsov, I. S., and Popandopulo, G. K.: 1976, presented at the 19th COSPAR meeting, Philadelphia.

Masursky, H., Kaula, W. M., McGill, G. E., Pettengill, G. H., Phillips, R. J., Russell, C. T., Schubert, G., and Shapiro, I. I.: 1977, this volume, p. 431.

McElroy, M. B.: 1969, J. Geophys. Res. 74, 29.

McElroy, M. B. and Strobel, D. F.: 1969, J. Geophys. Res. 74, 1118.

McElroy, M. B., Sze, N. D., and Yung, Y. L.: 1973, J. Atmos. Sci. 30, 1437.

Michel, F. C.: 1971, Rev. Geophys. Space Phys. 9, 427.

Moos, H. W., Fastie, W. G., and Bottema, M.: 1969, Astrophys. J. 155, 887.

Murray, B. C., Belton, M. J. S., Danielson, G. E., Davies, M. E., Gault, D., Hapke, B., O'Leary, B., Strom, R. G., Suomi, V., and Trask, N.: 1974, Science 183, 1307.

Nagy, A. F., Liu, S. C., Donahue, T. M., Atreya, S. K., and Banks, P. M.: 1975, Geophys. Res. Lett. 2, 83.

Orville, P.: 1974, in J.E. Hansen (ed.), The Atmosphere of Venus, NASA SP-382, 190.

Pike, R. J.: 1974, Geophys. Res. Lett. 1, 291.

Pollack, J. B., Erickson, E. F., Goorvitch, D., Baldwin, B. J., Strecker, D. W., Witteborn, F. C., and Augason, G. C.: 1975, J. Atmos. Sci. 32, 1140.

Pollack, J. B., Erickson, E. F., Witteborn, F. C., Chackerian, C., Jr., Summers, A. L., Van Camp, W., Baldwin, B. J., Augason, G. C., and Caroff, L. J.: 1974, Icarus 23, 8.

Pollack, J. B. and Morrison, D.: 1970, Icarus 12, 376.

Pollack, J. B. and Young, R.: 1975, J. Atmos. Sci. 32, 1025.

Prinn, R. G.: 1971, J. Atmos. Sci. 28, 1058.

Prinn, R. G.: 1974, J. Atmos. Sci. 31, 1691.

Prinn, R. G.: 1975, J. Atmos. Sci. 32, 1237.

Rogers, A. E. E., Ingalls, R. P., and Pettengill, G. H.: 1974, Icarus 21, 237.

Rossow, W. B. and Sagan, C.: 1975, J. Atmos. Sci. 32, 1164.

Rottman, E. J. and Moos, H. W.: 1973, J. Geophys. Res. 78, 8033.

Rumsey, H. C., Morris, G. A., Green, R. R., and Goldstein, R. M.: 1974, Icarus 23, 1.

Russell, C. T.: 1976, Geophys. Res. Lett., 3, 125.

Sagan, C.: 1975, J. Atmos. Sci. 32, 1097.

Saunders, R. S., Friedman, L. D., and Thompson, T. W.: 1973, Am. Inst. Aeronautics and Astronautics Paper No. 73-580, 11 pp.

Schubert, G., Counselman, C. C., III, Hansen, J., Limaye, S. S., Pettengill, G., Seiff, A., Shapiro, I. I., Suomi, V. E., Taylor, F., Travis, L., Woo, R., and Young, R. E.: 1977, this volume, p. 357.

Shapiro, I. I., Pettengill, G. H., Sherman, G. N., Rogers, A. E. E. and Ingalls, R. P.: 1973, Science 179, 473.

Sill, G. T.: 1972, Comm. Lunar Planetary Lab., No. 171, 191.

Simpson, J. A., Eraker, J. H., Lamport, J. E., and Walpole, P. H.: 1974, Science 183, 1318.

Sinclair, A. C. E., Basart, J. P., Buhl, D., Gale, W. A., and Liwshitz, M.: 1970, Radio Sci. 5, 347.

Smith, W. B., Ingalls, R. P., Shapiro, I. I., and Ash, M. E.: 1970, Radio Sci. 5, 411. 
Spreiter, J. R., Summers, A. L., and Rizzi, A. W.: 1970, Planet. Space Sci. 18, 1281.

Stone, P. H.: 1975, J. Atmos. Sci. 32, 1005.

Strickland, D. J.: 1973, J. Geophys. Res. 78, 2827.

Sze, N. D. and McElroy, M. B.: 1975, Planet Space Sci. 23, 703.

Traub, W. A. and Carleton, N.P.: 1974, in A. Woszczyk and C. Iwaniszewska (eds.) Exploration of the Planetary System, Reidel, Dordrecht, p. 223.

Traub, W. A. and Carleton, N. P.: 1975, J. Aimos. Sci. 32, 1045.

Vasiberg, O. L., Romanov, S. A., Smirnov, V. N., Karpinsky, I. P., Khayanov, B. I., Polenov, B. V., Bogdanov, A. V., and Antonov, N. M.: 1976, Proc. Int. Sym. on Solar-Terrestrial Physics, in press.

Van Allen, J. A., Krimigis, S. M., Frank, L. A., and Armstrong, T. P.: 1967, Science 158, 1673.

Vinogradov, A.P., Surkov, Yu. A., Andreichikov, B. M., Kalinkina, O. M., and Grechischeva, I. M.: 1971, in C. Sagan, T. C. Owen, and H. J. Smith (eds.), Planetary Atmospheres, Reidel, Dordrecht, p. 3.

Vinogradov, A. P., Surkov, Yu. A., and Kirnozov, F. F.: 1973, Icarus 20, 253.

Warnock, W. W. and Dickel. J. R.: 1972, Icarus 17, 682.

Wasserman, L. H, and Veverka, J.: 1973, Icarus 20, 322.

Whitten, R. C.: $1969, J$. Geophys. Res. 74, 5623.

Whitten R. C. and Colin, L.: 1974, Rev. Geophys. Space Phys. 12, 155.

Wofsy, S. C. and Sze, N. D.: 1975, in B. M. McCormac (ed.), Atmospheres of Earth and the Planets, Reidel, Dordrecht, p. 369.

Young, A.T.: 1973, Icarus 18, 564.

Young, A. T.: 1975, J. Atmos. Sci. 32, 1125.

Young, L. D. G.: 1972, Icarus 17, 632.

Young, R. E. and Schubert, G.: 1973, Planet. Space Sci. 21, 1563.

Zipf, E. C.: 1975, 1975, Concerning the physics and chemistry of excited states: Some new frontiers, paper presented at the XVI International Union of Geodesy and Geophysics General Assembly, Grenoble, France. 